\title{
PROMOVENDO A AUTOESTIMA NA GESTAÇÃO: FOCO NO ACOLHIMENTO
}

Jamila Geri Tomaschewski-Barlem¹, Simoni Saraiva Bordignon ${ }^{2}$, Cesar Francisco Silva da Costa ${ }^{3}$, Carla de Oliveira da Costa ${ }^{4}$, Edison Luiz Devos Barlem ${ }^{5}$

Objetivo: relatar a utilização de ensaios fotográficos na promoção da autoestima de gestantes, tomando por objeto a experiência de um projeto de extensão desenvolvido em uma Unidade Básica de Saúde da Família. Metodologia: as ações realizadas visaram a utilização da fotografia na promoção da autoestima da gestante, estimulando sua participação no Grupo de Gestantes e no processo completo de pré-natal. Resultado: acreditamos que foi possível proporcionar às gestantes uma interação com o bebê de maneira prazerosa, valorizando suas crenças, valores, projetos pessoais, histórias de vida, sentimentos e expectativas frente à gestação. Conclusão: as atividades em grupo devem ser pensadas como meio de oportunizar a socialização, a integração e trocas de experiências.

Descritores: Enfermagem; Obstetrícia; Assistência; Gestante.

\section{PROMOTING SELF-ESTEEM DURING PREGNANCY: FOCUS ON USER EMBRACEMENT}

Objective: this paper aimed at reporting the utilization of photo shoots to promote self-esteem in pregnant women. Its object was the experience of an extension project developed at a Basic Family Health Unit. Methodology: the actions accomplished aimed at the use of photography for the promotion of self-esteem in pregnant women, stimulating their participation in the Pregnant Women Group and in the whole prenatal process. Results: we believe it was possible to provide the pregnant women with an interaction with their babies in a pleasurable way, valuing their beliefs, values, personal projects, life experiences, feelings and expectations for pregnancy. Conclusion: group activities should be thought of as a meant to create opportunities for socialization, integration and exchange of experiences.

Descriptors: Prenatal Care, User Embracement, Family Health, Photography.

\section{PROMOCIÓN DE LAAUTOESTIMA EN EL EMBARAZO: ENFOQUE EN EL ACOGIMIENTO}

Objetivo: este estudio tuvo como objetivo relatar el uso de ensayos fotográficos en la promoción de la autoestima de las mujeres embarazadas, teniendo por objeto la experiencia de un proyecto de extensión desarrollado en una unidad básica de salud de la familia. Metodologia: las acciones realizadas visaron la utilización de la fotografía en la promoción de la autoestima de las mujeres embarazadas, avivando su participación en el grupo de mujeres embarazadas y en el proceso completo de la atención prenatal. Resultados: creemos que fue posible proporcionar a las mujeres embarazadas una interacción con el bebé tan agradable, valorando sus creencias, valores, proyectos personales, historias de vida, sentimientos y expectativas en relación al embarazo. Conclusión: actividades de grupo deben ser considerados como un medio para crear oportunidades para la socialización, la integración y el intercambio de experiencias.

Descriptores: Atención Prenatal, Acogimiento, Salud de la Familia, Fotografía.

${ }^{1}$ Enfermeira. Doutora em Enfermagem. Docente da Escola de Enfermagem da Universidade Federal do Rio Grande - FURG. 2Enfermeira. Doutoranda em Enfermagem d FURG. Bolsista FAPERGS. Email: simonibordignon@gmail.com

${ }^{3}$ Enfermeiro. Doutorando em Enfermagem. Docente da FURG.

${ }^{4}$ Enfermeira. Coordenadora da equipe Estratégia de Saúde da Familia, Rio Grande.

${ }^{5}$ Enfermeiro. Doutor em Enfermagem. Docente da EEnf-FURG. Email: ebarlem@gmail.com 


\section{INTRODUÇÃO}

O presente artigo propõe-se relatar a utilização de ensaios fotográficos na promoção da autoestima de gestantes, tomando por objeto a experiência de um projeto de extensão desenvolvido em uma Unidade Básica de Saúde da Família (UBSF) no município de Rio Grande - RS, em parceria entre a Escola de Enfermagem, da Universidade Federal do Rio Grande (FURG), e a Secretaria Municipal da Saúde (SMS). O projeto, intitulado "Foco no acolhimento: gestantes em cena", utiliza sessões de fotografias e grupos de gestantes como meio de promover a autoestima na gestação.

A gestação caracteriza-se como sendo um período em que as mulheres se encontram mais suscetíveis, sofrendo modificações físicas e psicológicas, ou mesmo, sociais ${ }^{(1)}$, as quais, muitas vezes, refletem na sua autoestima, podendo trazer consequências tanto para a mãe quanto para o bebê(2): "A autoestima pessoal diz respeito à avaliação positiva ou negativa que o indivíduo faz de si mesmo, constituindo-se, assim, em um aspecto central do eu, que desempenha papel fundamental no processo de construção da identidade"(3).

O fato de estar grávida pode ser visto como motivo de alegria e orgulho para algumas mulheres, principalmente quando há o desejo de engravidar(4). No entanto, as modificações ocorridas durante a gestação ocasionam, muitas vezes, certo desconforto entre as mulheres, principalmente, em relação à aparência.

Nessa perspectiva, o período pré-natal é um momento de preparação tanto para o nascimento do bebê quanto para a maternidade, sendo, também, uma época de muito aprendizado. Ele proporciona aos profissionais de saúde a possibilidade de desenvolver a educação em saúde como dimensão do cuidado, assumindo a condição de educadores que trocam e compartilham saberes, buscando instigar na mulher sua autoconfiança e autoestima para viver a gestação, o parto e o puerpério(5)

É necessário que os profissionais de saúde ultrapassem os limites do modelo clínico visando atender as necessidades dos indivíduos na sua integralidade ${ }^{(5)}$, estimulando sua relação saudável com o meio, nas diferentes fases da vida. É fundamental que a gestante e a família sejam acolhidas pela equipe de saúde, desde o primeiro contato com a unidade de saúde na qual está sendo assistida. Dessa forma, o acolhimento deve ser considerado no atendimento à gestante com o mesmo sentido que a gestação tem para ela e sua família, uma vez que é a partir dessa fase que se inicia o desenvolvimento do vínculo com bebê $\hat{e}^{(6)}$.

Os avanços tecnológicos possibilitam aos profissionais de saúde a utilização de inúmeros recursos digitais, fazendo-se necessária uma reflexão crítica acerca dos potenciais benefícios e limites da inclusão da tecnologia no cotidiano profissional. A fotografia, entre esses avanços, destaca-se como uma importante ferramenta nas ações dos profissionais de saúde, sendo muito utilizada em análise diagnóstica ou acompanhamento e tratamento de lesões( ${ }^{(7)}$. No entanto, pode constituir-se, também, como relevante recurso no âmbito da promoção da saúde, ampliando sua compreensão, mobilizando sentimentos $e$ emoções.

Assim, por meio de metodologias participativas, podem ser promovidas ações educativas que possibilitem, à mulher, a descoberta de seu corpo, possibilitando que o seu conhecimento venha a ser compartilhado nos grupos promovidos pelos serviços de saúde e junto à comunidade ${ }^{(8)}$, fortalecendo, ainda, o acolhimento e a adesão às consultas de pré-natal( ${ }^{(8)}$.

É nessa perspectiva inovadora que o projeto de extensão "Foco no acolhimento: gestantes em cena" vem desenvolvendo um trabalho articulado à utilização da fotografia na promoção da autoestima na gestação. Ele estimula a participação no Grupo de Gestantes como também no processo completo de pré-natal, sendo executado por docentes e discentes de enfermagem e equipe multiprofissional de saúde da família.

\section{METODOLOGIA}

Em agosto de 2009 teve início o ensaio fotográfico no Grupo de Gestantes em uma Unidade Básica de Saúde da Família no município de Rio Grande - RS, a partir da ideia de promover a autoestima das gestantes e estimular a participação no grupo e nas consultas de pré-natal. As intervenções junto às gestantes são planejadas e implementadas pelos estudantes de Graduação em 
Enfermagem da FURG que compõem o projeto, com apoio e participação da equipe da UBSF, formada por médico, enfermeiro, técnicos de enfermagem e agentes comunitários de saúde (ACS). Devido à adesão e motivação por parte da equipe de saúde e aceitação da comunidade atendida, o projeto ganhou continuidade, tornando-se, em junho de 2010 um projeto de extensão, que vem expandindo-se para outras duas UBSF's, ambas do município de Rio Grande. Conta, ainda, com a inclusão de acadêmicos de outros cursos de graduação, como Educação Física e, futuramente, de Psicologia.

$O$ projeto atende as gestantes cadastradas na UBSF e consiste em discutir e promover no Grupo de Gestantes a autoestima e, depois, realizar um ensaio fotográfico. Mensalmente, as gestantes são convidadas a participar do grupo em que são trabalhadas questões como a autoestima e a valorização da mulher. Nos encontros do grupo, também, é estimulada a realização das consultas de pré-natal e são esclarecidos assuntos, como a importância do aleitamento materno, os cuidados no decorrer da gestação e com o bebê, informações sobre exames realizados, evolução da gestação, sexualidade e outras dúvidas que possam surgir neste período.

Após as reuniões do Grupo de Gestantes, é promovido um ensaio fotográfico, desenvolvido em um espaço na própria UBSF, para confecção de um book fotográfico, sendo esse disponibilizado às gestantes através de CD e fotografia impressa. No projeto, já participaram 30 gestantes, com idades entre 15 e 36 anos, as quais mostraram-se estimuladas a integrar o grupo, mensalmente, a fim de acompanhar o desenvolvimento de sua gestação por meio das fotos, conviver com a equipe de saúde e com as demais gestantes que participam do grupo.

\section{RESULTADOS}

No primeiro momento, durante o encontro do grupo, percebemos sentimentos de timidez, insegurança e medo do desconhecido. Notou-se, ainda, distorções entre os papéis de mulher e mãe, pois nesta relação percebeu-se a desvalorização do ser mulher, por meio de relatos quanto à diminuição da vontade de cuidar da aparência, de arrumarse, ou, até mesmo, do desconhecimento das alterações fisiológicas do próprio corpo. No decorrer das discussões, foi estimulado o diálogo entre gestante e seu parceiro, além da própria família, buscando o apoio mútuo, considerando que, embora a gestação seja um período de mudanças, ela precisa abranger todas as facetas, desde o ser mãe à valorização do ser mulher.

A discussão e integração no grupo permitem à gestante compartilhar e multiplicar informações de saúde no seu ambiente coletivo. As interações suscitadas entre as integrantes do grupo e os profissionais da saúde formam uma rede que oportuniza a promoção da saúde com reflexos no individual-coletivo. A partir das vivências e experiências compartilhadas, as gestantes passam a compreender a gestação de maneira diferente, sentindo-se mais confiantes e próximas do seu bebê $\hat{e}^{(8)}$.

No segundo momento, durante a realização do ensaio fotográfico, utilizamos maquiagem e diferentes acessórios, que as gestantes poderiam escolher conforme suas preferências. Buscamos valorizar a mulher e sua "barriga", evidenciando este acontecimento tão especial e único na vida de cada uma. Deparamo-nos em cada flash com a empolgação, o brilho no olhar, a emoção por meio de expressões simples do ser humano como lágrimas e sorrisos.

Acreditamos que foi
possivel proporcionar às
gestantes uma interação com

o bebê de maneira prazerosa, valorizando suas crenças, valores, projetos pessoais, histórias de vida, sentimentos e expectativas frente à gestação. Ao receberem as fotos, observando e refletindo sobre seus significados, as gestantes pareciam surpresas com a própria beleza, verbalizando que se sentiam mais bonitas, femininas, incentivadas. Relatam que haviam aprendido a valorizar a condição de ser mãe e o crescimento e o desenvolvimento de seu bebê. Cabe destacar que as imagens dialogam com a realidade e com a representação dessa realidade, pois a fotografia se apresenta como uma fonte privilegiada de informação da realidade estudada e da visão de mundo dos participantes. A articulação imagem-realidade mostra-se potente no acesso a diferentes dimensões dos sujeitos e se constitui em uma estratégia de intervenção em várias problemáticas. Dessa forma, as narrativas visuais têm uma função estratégica, 
contribuindo para superar barreiras culturais ${ }^{(9)}$ entre profissional de saúde e usuário, permeados por significados revelados em emoção e afetividade.

Por meio dos sentimentos manifestados e relatados pelas gestantes, foi possivel desvelar a experiência vivenciada por elas, apontando a diversidade de significados e sentimentos que surgem duranteagestação. Esses constituem importante fonte de informação que proporciona aos profissionais de saúde refletirem sobre seu papel como agentes promotores de saúde e ações a serem desenvolvidas.

Para as mulheres, a gestação e a maternidade traduzem significados e expectativas culturais e sociais muito amplas, as quais passam a integrar o imaginário social atreladas à saúde, à felicidade, à continuidade de sua existência e de sua família ${ }^{(10)}$. Assim, é necessário que as equipes de saúde atuem no sentido de potencializar o cuidado e a atenção dispensados ao binômio mãe/bebê, fortalecendo a educação em saúde de forma humanizada, proporcionado orientações e esclarecimento de dúvidas sobre os cuidados com a gravidez, o parto, o puerpério e os cuidados com o bebê $\hat{e}^{(10)}$ valorizando a gestação como um momento único e especial.

\section{CONCLUSÃO}

Percebemos a importância da realização dos trabalhos como este, a fim de que se promovam ações durante a gestação, garantindo a saúde e o bem-estar tanto da mãe, quanto do bebê. Tem ainda o mérito de estimular a participação nos grupos de gestantes e a realização completa do pré-natal, proporcionando, assim, uma gravidez saudável e tranquila, do período gestacional à chegada do novo membro à família.

Por meio deste trabalho, torna-se possível afirmar que pequenas ações podem transformar contextos, sentimentos, e modos de ver, rever, viver e reviver a gestação. Ainda, as atividades em grupo não devem ser pensadas apenas como uma forma de suprir a demanda de trabalho, mas, sim, como meio de oportunizar a socialização, a integração e as trocas de experiências e saberes entre os participantes.

Por fim, esperamos sensibilizar outros profissionais de saúde a incluírem em suas práticas cotidianas ações como esta, vivenciando experiências gratificantes, com potenciais benefícios para a clientela que assistem.

\section{REFERÊNCIAS}

1. Silva LS, Pessoa FB, Pessoa DTC, Cunha VCM, Cunha CRM, Fernandes CKC. Análise das mudanças fisiológicas durante a gestação: desvendando mitos. Revista Eletrônica FMB. 2015; 8(1):1-16.

2. Santos AB, Santos KEP, Monteiro GTR, Prado PR, Amaral TLM. Autoestima e qualidade de vida de uma série de gestantes atendidas em rede pública de saúde. Cogitare Enferm. 2015; 20(2):389-96.

3. Silva RA, Ores LC, Mondin TC, Rizzo RNR, Moraes IGS, Jansen K, Pinheiro RT. Transtornos mentais comuns e auto-estima na gestação: prevalência e fatores associados. Cad Saúde Pública. 2010; 26(9):1832-8.

4. Velho MTAC, Riesgo I, Zanardo CP, Freitas AP, Fonseca R. A reincidência da gestação na adolescência: estudo retrospectivo e prospectivo em regiẫo do sul do brasil. Saúde e Pesquisa. 2014; 7(2):261-73.

5. Ribeiro JF, Luz VL, Sousa AS, Silva GLL, Feitosa VC, Sousa MFA. Contribuição do pré-natal para o parto normal na concepção do enfermeiro da estratégia saúde da familia. Rev. Interd. 2016: 9(1):161-70.
6. Silva MZN. Andrade AB, Bosi MLM. Acesso e acolhimento no cuidado prénatal à luz de experiências de gestantes na Atenção Básica. Saúde Debate. 2014: 38(103):805-16

7. Galvão MTG, Alexandre HO, Dantas PB, Lima ICV, Lopes EM. Uso da fotografia no processo do cuidar: tendências das ações de enfermagem. Cienc. enferm. 2013; XIX(3):31-3.

8.Lima PVSF, Soares ML, Fróes GDR, Machado JR, Santos SM, Alves ED. Liga de humanização do parto e nascimento da Universidade de Brasilia: relato de experiência. Rev Gestão \& Saúde. 2015; 6(3):2783-98.

9. Gomes MAF, Dimenstein M. Pesquisa qualitativa em Psicologia e Saúde Coletiva: experimentações com o recurso fotográfico. Psicol. cienc. prof. 2014; 34(4):804-20.

10. Moura EL, Kimura AF, Praça NS. Ser gestante soropositivo para o Virus da Imunodeficiência Humana: uma leitura à luz do Interacionismo Simbólico. Acta Paul Enferm. 2010; 23(2):206-11. 